\title{
PEMIMPIN SEBAGAI GEMBALA
}

Eli Wilson Ipaq ${ }^{1}$

\begin{abstract}
ABSTRAK
Istilah pemimpin gembala adalah suatu analogi dogmatis yang menggambarkan peranan dan harapan terhadap para pemimpin, secara khusus para pemimpin gereja. Karena secara Alkitabiah, analisis dan rumusan tentang kepemimpinan gembala adalah suatu konsep pendekatan pelayanan yang menjunjung tinggi nilai-nilai rohani, kepemimpinan hamba, moralitas, sosial dan etika. Dengan pendekatan yang menjadi ciri khasnya adalah kasih, bukan atas kekuasaan, politik dan uang (Yohanes 21:15-17).

Penegasan ini tersirat di dalam gagasan Yesus seperti yang terdapat dalam Yohanes 21:15-17 yakni: Pertama: "gembalakanlah domba-domba-Ku." Kedua: gembalakan kawanan domba dengan kasih Allah.

Dengan terus memperhatikan prinsip-prinsip fundamental yang aktual, Alkitabiah dalam membangun strategi dan melaksanakan fungsinya sebagai pemimpin pembaharu.
\end{abstract}

Kata kunci : pemimpin, gembala, Yohanes 21:15-17

${ }^{1}$ Ketua STT Tenggarong dan dosen STT Tenggarong. 


\section{PENDAHULUAN}

\section{Pemahaman Terhadap Pemimpin Gembala}

Istilah pemimpin gembala adalah suatu analogi dogmatis yang menggambarkan peranan dan harapan terhadap para pemimpin, secara khusus para pemimpin gereja. Karena secara Alkitabiah, analisis dan rumusan tentang kepemimpinan gembala adalah suatu konsep pendekatan pelayanan yang menjunjung tinggi nilai-nilai rohani, kepemimpinan hamba, moralitas, sosial dan etika. Dengan pendekatan yang menjadi ciri khasnya adalah kasih, bukan atas kekuasaan, politik dan uang (Yohanes 21:15-17). Dalam Perjanjian Lama dan Perjanjian Baru, penggembalaan adalah kiasan yang lazim dan yang merujuk pada gaya kepemimpinan. Itulah sebabnya secara teoritis, pemimpin gembala adalah salah satu model kepemimpinan yang harus dikembangkan dan diaktualisasikan dalam segala bentuk dan konteks pelayanan modern. Disamping itu, karena jiwa dan ciri khasnya, istilah pemimpin gembala telah menjadi kiasan bagi kepemimpinan universal. Prof. Dr. Alaidin Koto, MA. Mengungkapkan dalam tulisannya dengan mengutip satu kata dalam bahasa Arab, yaitu: "Ra-in yang berarti secara hurufiah bahwa penggembala mewakili kata pemimpin, yang setiap hari sejak bangun pagi sampai malam memikirkan keselamatan dan kesejahteraan kawanan dombanya."

Pemimpin Gembala Dalam Pengertian Dogma Alkitabiah:

1. Gembala adalah pemimpin dan penasehat bagi Jemaat.

2. Pemimpin gembala adalah bapa dan ibu rohani bagi jemaat.

3. Pemimpin gembala adalah figur panutan bagi jemaat.

4. Pemimpin gembala adalah pemimpin yang melayani bukan memerintah.

5. Pemimpin gembala adalah pemimpin yang dipilih dan ditetapkan oleh Allah.

6. Pemimpin gembala adalah seorang pengkhotbah dan guru bagi jemaat.

7. Pemimpin gembala adalah seorang pemimpin yang lemah lembut dan panjang sabar.

8. Pemimpin gembala adalah perpanjangan tangan Allah.

\footnotetext{
${ }^{2}$ Alaidin Koto, Islam Dan Kepemimpinan Di Indonesia. Diakses tanggal 23 Januari 2013; tersedia di http://www.frreykoto.wordpress.com
} 
9. Pemimpin gembala adalah pemimpin yang memberi makan, memimpin, melindungi, memelihara, menjaga dan membangun serta membela umatnya.

10. Pemimpin gembala adalah pemimpin yang melaksanakan fungsi keimamatan dan kenabian bagi umatnya, yang setiap saat siap mengajar dan bersyafaat bagi umatnya.

11. Pemimpin gembala adalah pemimpin yang dikhususkan dan diurapi oleh Allah. (Matius 10:1-4)

12. Pemimpin gembala dalam konteks Israel adalah para pemimpin, para imam, para nabi, orang-orang bijak, para tua dan orang tua dalam rumah tangga (Hak 17:6; 21:25; Yer 18:18).

Kalau demikian, berarti kita semua tergolong dalam apa yang disebut pemimpin gembala. Memperhatikan pemahaman di atas, maka dapat dikatakan bahwa arti dan fungsi pemimpin gembala sangat melekat pada arti namanya sendiri.

\section{GAGASAN DAN MANDAT YESUS TENTANG PEMIMPIN GEMBALA BERDASARKAN YOHANES 21:15-17}

\section{Gembalakanlah Domba-Domba-Ku ${ }^{3}$}

Dalam terjemahan bahasa aslinya: " $\lambda \varepsilon \gamma \varepsilon i ́$ $\alpha v \tau \omega$ Пoí $\mu \alpha i ́ v \varepsilon \tau \alpha$

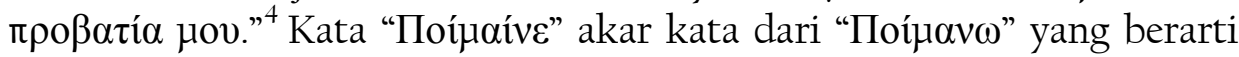
"To feed: memberi makan, Tend a plock: merawat, memelihara, mengurus kawanan domba atau jemaat." Selain itu terdapat penekanan bahwa perhatian gembala harus tertuju pada kawanan domba itu. Pernyataan ini berbicara dalam bentuk imperative, present active, yang maknanya bahwa tugas penggembalaan itu adalah suatu perintah yang sangat urgen, dalam arti bahwa pekerjaan itu harus dikerjakan hari ini juga, saat ini dan seterusnya. Apa yang dimaksud di atas menunjukkan betapa pentingnya tugas penggembalaan itu karena sangat berhubungan dengan hidup atau matinya kawanan domba, atau keselamatan kawanan itu. Inilah inti yag diharapkan oleh Yesus terhadap para murid agar mereka dapat melihat kawanan domba atau umat manusia itu seperti Yesus melihat mereka. Mereka perlu segera diberi makan, dipimpin, dipelihara, dirawat, sebab kalau tidak ada yang akan mati, dicuri, dirampas, diterkam oleh binatang buas.

\footnotetext{
${ }^{3}$ Yohanes 21:15-17

${ }^{4}$ B. Canon Philip, Interlinear Greek-English New Testament (Michigan: Reglacy Reference Library, 1976), 246.

${ }^{5}$ K. Harold Moulton, The Analytical Greek Lexicon Revised (Michigan: Reglacy Reference Lybrary, 1990), 48.
} 


\section{Gembalakan Kawanan Domba Itu Dengan Kasih Allah}

Pengajaran Yesus yang terdapat dalam Yohanes 21:15-19, ada kata perintah bahwa dalam menggembalakan kawanan domba itu, tidak cukup dengan kasih filia (kasih kekeluargaan/persaudaraan, tetapi harus

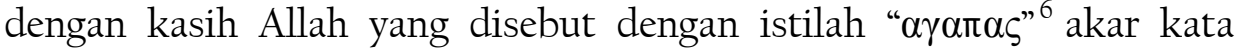

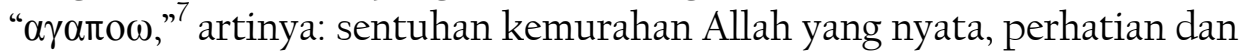
keprihatinan Allah, kehadiran-Nya yang menyukakan, kemurahan hati yang tanpa batas. Itu sebabnya sampai tiga kali pertanyaan yang sama dilontarkan Yesus kepada Petrus. "Simon anak Yohanes apakah engkau mengasihi Aku lebih daripada mereka ini?" ${ }^{8}$ Pada pertanyaan yang ketiga kalinya barulah Petrus merasa terintrogasi dan terkoreksi, dan memahami maksud Yesus dengan kasih yang sesungguhnya. Sehingga dengan sedih ia menjawab: "Tuhan, Engkau tahu segala sesuatu, Engkau tahu bahwa aku mengasihi Engkau." Tuntutan untuk mengasihi Yesus di sini berarti: menaati maksud dan rencana-Nya. Dengan rela dan tulus hati melakukan perintah-Nya. Tuntutan untuk mengasihi Yesus di sini juga berarti bahwa setiap orang yang akan memberi diri untuk melayani Tuhan, syarat utamanya ialah harus mengasihi Yesus terlebih dahulu dan terus meneladani Yesus yang adalah Gembala Agung itu.

Dalam Yohanes 10:1-21, Yesus memberikan suatu analogi tentang pemimpin gembala, yakni gembala yang baik dan gembala yang tidak baik.

Pertama, gembala yang baik, ia mengenal domba-dombanya dan dombadombanya mengenal dia (10:1-5). Ia memimpin, memelihara, melindungi dan memberi makan domba-dombanya (10:7-10). Selain itu karena kasihNya, Ia memberikan nyawanya bagi domba-dombanya (10:11). Dalam teks ini Yesus menyatakan bahwa Dialah gembala yang baik itu.

Kedua, gembala yang tidak baik (10:11-12) disebut dengan istilah gembala upahan. Dia tidak merasa memiliki terhadap domba-domba itu, ketika melihat serigala datang, ia meninggalkan domba-domba itu lalu lari, sehingga serigala menerkam dan menceraiberaikan domba-domba itu.

Bilamana kita menganalogi pengajaran Yesus tantang gembala dengan iklim penggembalaan masa kini, kita akan menemukan berbagai permasalahan yang perlu menjadi catatan bagi pengembangan pelayanan penggembalaan agar ke depan menjadi lebih baik. Contoh kecil, saya sering mendapatkan masukan-masukan dari beberapa rekan saya yang adalah anggota jemaat, di mana mereka mengeluh terhadap perilaku gembalanya. Ada jemaat yang kecewa dengan perilaku gembala yang tidak menunjukkan jati diri sebagai pemimpin rohani, terlalu otoriter,

\footnotetext{
${ }^{6}$ Moulton, The Analytical Greek Lexicon Revised, 48.

${ }^{7}$ Ibid., 48.

${ }^{8}$ Ibid
} 
menciptakan konflik, malas melakukan perkunjungan, sehingga kehadiran jemaat di ibadah menurun, selain itu tidak jujur dan tidak konsisten antara kata dan tindakan. Terkadang kehadiran gembala justru menjadi sumber masalah, bukan bagian dari solusi. Sang gembala tidak punya hati gembala dan tidak mau belajar menjadi gembala yang baik seperti Yesus. Orientasi pelayanan juga hanya pada keuntungan materi dan pada rasa aman dan nyaman karena ada pekerjaan. Belum lagi keluarga (istri) yang tidak menjunjung tinggi pelayanan. Filosopi pelayanan rohani tidak dipahami oleh istri, sehingga istri hanya menuntut dilayani dan bukan untuk melayani.

Sebaliknya, ada persoalan yang sering menyebabkan semakin komplitnya persoalan dalam penggembalaan yaitu sering kali ada jemaat yang hanya menuntut agar para gembala menjadi gembala yang baik, tetapi tidak berusaha menjadi kawanan domba yang baik. Terkadang gembala dikritik habis-habisan, dicerca, diabaikan, direndahkan, dan hak-haknya secara materi nayris tidak diperhatikan. Sehingga terkadang hamba Tuhan diidentifikasi dengan kemiskinan. Saya teringat dengan salah satu statement Bapak Prof. Dr. Wim Poli, dalam orasi ilmiah yang beliau sampaikan pada tahun 2007 di STT Tenggarong. Beliau menyatakan bahwa "Ada banyak gereja yang masih mengidolakan Lazarus yang miskin." Maksudnya semakin miskin seseorang, terutama hamba Tuhan, maka dianggap semakin rohanilah dia. Tentu ini dilatarbelakangi oleh suatu pandangan yang keliru dan terlalu eksklusif. Pengajaran Yesus yang terungkap dalam Injil Lukas 16:19-31, bukan melarang orang percaya memiliki kekayaan tetapi yang dilarang adalah jangan mencontohi sifat ketamakan, kesombongan, mementingkan diri sendiri seperti orang kaya itu. Lebih dari itu, ia tidak memiliki kasih.

Kalau demikian apakah solusinya? Dalam melaksanakan mandat penggembalaan seperti yang terungkap dalam Yohanes 21:15-17, teristimewa di tengah-tengah terjadinya perubahan pada era dan pasca modern ini, ada beberapa prinsip yang harus diperhatikan, yakni:

Pertama: "Jabatan penggembalaan adalah panggilan untuk melayani.", (The Dignity of Calling and Ministry).

Kuasa yang Allah berikan kepada seorang pemimpin gembala bukan untuk memerintah, tetapi untuk melayani karena Allah yang terlebih dahulu melayani kita. Itu sebabnya Daud menyatakan "Tuhan gembala yang baik" (Mazmur 23:1-6), karena Ia terlebih dahulu melayani manusia.

\footnotetext{
${ }^{9}$ W. I. M. Poli, Orasi Ilmiah di STT Tenggarong (Tenggarong: STT Tenggarong, September 2007).

${ }^{10}$ Makmur Halim, Gereja di Tengah-tengah Terjadinya Perubahan (Malang: Yayasan Gandum Mas, 2000), 133.
} 
Kedua: "Era Pasca Modern merupakan tantangan bagi Pelayanan Pastoral"" (The Chalengges of Pastoral Ministry in Post modern Era)

Tantangan besar di era modern ini adalah karena terjadinya perubahan yang sangat cepat karena kemajuan tekhnologi. Sehingga menyebabkan terjadinya pergeseran nilai budaya, moral, pola hidup dan cara berpikir manusia. Itu sebabnya Charles Darwin pernah menyatakan bahwa, "Spesies yang bisa bertahan dalam kehidupan ini bukanlah spesies yang paling kuat, bukan pula yang paling cerdas, tetapi yang paling bisa bertahan dengan perubahanlah yang bakal bertahan."

Karena tantangan utama adalah: bilamana seseorang tidak siap berhadapan dengan perubahan dan mengimbangi perubahan yang terjadi. Karena itu hal ini juga menjadi tantangan bagi para pemimpin gembala, yaitu bagaimana memimpin umat ini di tengah terjadinya perubahan, agar ia tidak digilas oleh perubahan itu sendiri.

Ketiga: Pemimpin Gembala mengemban Otoritas dari Allah (1 Korintus 10:8; 13:16)

Otoritas yang perlu dipahami oleh para pemimpin gembala antara lain, yaitu:

1. Kuasa yang dikarunia Allah dalam memperlengkapi para pemimpin.

2. Kuasa untuk melakukan fungsi dan tugas kepemimpinan.

3. Kuasa untuk melakukan reformasi dan transformasi bagi umat Tuhan secara menyeluruh.

4. Kuasa untuk melakukan pelayanan pemberitaan Injil.

5. Kuasa untuk membangun bukan meruntuhkan, agar terjadi pertumbuhan untuk mencapai kedewasaan, serta terbentuknya suatu tatanan pelayanan yang lebih baik.

Keempat: Pemimpin gembala harus konsisten dengan dogma Alkitabiah.

Abad 21 masih dipengaruhi oleh era kebangkitan agama-agama, denominasionalisme, serta supranaturalisme di seluruh dunia, khususnya di Indonesia. Sejalan dengan perkembangan itu, gereja semakin gencar berhadapan dengan isue Teologi dan dogma yang menyesatkan. Seperti contoh: munculnya isue Teologi Perdukunan, yang dipelopori oleh salah satu aliran gereja di Jakarta, yang berupaya mengadikodrati simbol-simbol yang ada di dalam sakramen gereja, dan banyak lagi yang lain.

Kondisi inilah yang membuat para pemimpin gembala harus kuat dan konsisten dengan dogma Alkitabiah, dengan tujuan agar "Inerensi

\footnotetext{
${ }^{11}$ Ibid, 341.

${ }^{12}$ Rosid Murwanto, "Charles Darwin"; Diakses tanggal 23 Januari 2013; tersedia di http://www.blogspot.com/2013/04/carles-darwin.html
} 
Alkitab"13 tidak diragukan dan ditolak. Sebab berdasarkan fakta sejarah "Kerusakan Gereja disebabkan oleh dogma yang rusak." It Itu sebabnya Martin Luther menyatakan bahwa: "Kerusakan gereja hanya dapat diperbaiki jikalau dogma dikembalikan kepada Alkitab."15

Kelima: Pemimpin Gembala harus memiliki Keberanian

Di dalam suatu dinamika kepemimpinan, terkadang pemimpin ada pada posisi yang sulit dalam mengambil keputusan dan tindakan. Ragu dan kompromistis, yang akhirnya tidak dapat menyelesaikan masalah karena tidak ada keberanian. Bill Newman, dalam suatu tulisannya menyatakan bahwa "keberanian harus didasarkan pada pandangan yang dipahami benar tanpa keraguan dan bersedia menerima resiko apapun, seorang pemimpin tanpa keberanian bukanlah pemimpin sejati." 16 Sehingga dapat dikatakan bahwa seorang pemimpin pembaharu tidak hanya karena kecerdasannya, tetapi lebih karena keberaniannya. Kolonel Aji Suaji, seorang perwira tinggi dalam pemerintahan SBY menyatakan "Kita tidak perlu pemimpin yang sangat cerdas sebab terkadang kecerdasan menghambat keberanian untuk bertindak." ${ }^{17}$ Karena keberanian yang diperlukan dari seorang pemimpin selain bertujuan untuk kecepatan dalam bertindak dan menyelesaikan masalah, juga mencerminkan sikap: konsisten, disiplin, dan kemandirian seorang pemimpin.

\section{PENUTUP}

\section{Kesimpulan}

Istilah pemimpin gembala adalah salah suatu analogi dogmatis yang menggambarkan peranan dan harapan terhadap para pemimpin masa kini,khususnya bagi para pemimpin gereja.

Penegasan ini tersirat di dalam gagasan Yesus seperti yang terdapat dalam Yohanes 21:15-17 yakni:

Pertama: "gembalakanlah domba-domba-Ku."

Kedua: gembalakan kawanan domba dengan kasih Allah.

Dengan terus memperhatikan prinsip-prinsip fundamental yang aktual, Alkitabiah dalam membangun strategi dan melaksanakan fungsinya sebagai pemimpin pembaharu.

\footnotetext{
${ }^{13}$ Jurnal Teologi Reformed Indonesia ( Jakarta: STT Reformed Indonesia, 2011), 21.

${ }_{15}^{14}$ Jurnal Teologi Reformed Indonesia (Jakarta: STT Reformed Indonesia, 2011), 21.

${ }^{15}$ Ibid., 21.

${ }^{16}$ Aaji Suaji, Diakses tanggal 23 Januari 2013; tersedia di http://www.kabarnet.wordpress.com/2010/09/06/pemimpin-keberanian dan

${ }^{17}$ Ibid.
} perubahan. 


\title{
KEPUSTAKAAN
}

\author{
Buku-buku
}

Halim, Makmur. Gereja di Tengah-tengah Terjadinya Perubahan. Malang: Yayasan Gandum Mas, 2000.

Jurnal Teologi Reformed Indonesia. Jakarta: STT Reformed Indonesia, 2011.

Moulton, K. Harold. The Analytical Greek Lexicon Revised. Michigan: Reglacy Reference Lybrary, 1990.

Murwanto, Rosid. Rosid Murwanto. Blogspot.com/2013/04/carlesdarwin.html.

Philip, B. Canon. Interlinear Greek-English New Testament. Michigan: Reglacy Reference Library, 1976.

Poli, W. I. M. Orasi Ilmiah di STT Tenggarong. Tenggarong: STT Tenggarong, September 2007.

\section{Internet}

Aaji Suaji, Diakses tanggal 23 Januari 2013; tersedia di http://www.kabarnet.wordpress.com/2010/09/06/pemimpinkeberanian dan perubahan.

Koto, Alaidin. Islam dan kepemimpinan di Indonesia Frreykoto.wordpress.com, Jan, 23/2013. 